\title{
Duas espécies novas de Cyphonia Laporte da região central do Brasil (Homoptera, Membracidae, Smiliinae) ${ }^{1}$
}

\author{
Randal Lopes Barreira ${ }^{2}$ \\ Albino Morimasa Sakakibara ${ }^{3}$
}

\begin{abstract}
Two new species of Cyphonia Laporte, 1832 from the central region of Brazil (Homoptera, Membracidae, Smiliinae). Cyphonia cabetteae sp. n. and C. xavantina sp. n., both from Nova Xavantina, Mato Grosso, are described and illustrated. These two new species are very close to Cyphonia intermedia Sakakibara, 1968 and to Cyphona clavata (Fabricius, 1787), concerning their overall aspects.

KEY WORDS. Homoptera, Membracidae, Smiliinae, Cyphonia, descriptions
\end{abstract}

Cyphonia Laporte, 1832, foi revisado por SAKAKIBARA (1968) que o considerou formado por dois subgêneros distintos, apresentando, respectivamente os processos supra-umerais simples e processos supra-umerais bifurcados: Cyphonia (Cyphonia) Laporte, 1832 e Cyphonia (Eucyphonia) Sakakibara, 1968. KopP \& YONKE (1979), revisando a tribo Ceresini, elevaram Eucyphonia para a categoria gênero; listaram para Eucyphonia, oito espécies e para Cyphonia, 26 espécies. Acrescentam-se agora, duas espécies novas para Cyphonia, descritas a seguir.

\section{Cyphonia cabetteae sp. $\mathbf{n}$.}

Figs 1, 3-7

Diagnose. Coloração geral negra, com manchas amareladas; metopídio verrucoso; processos supra-umerais robustos, recurvados, de comprimento superior à largura da cabeça; processo posterior com os lóbulos laterais aproximadamente do mesmo tamanho que o mediano, mais ou menos piriformes.

Medidas (mm). Macho (holótipo)/fêmea. Comprimento total 6,17/6,17; comprimento do pronoto 5,17/5,42; largura entre os ângulos umerais $1,75 / 1,83$; distância entre os ápices dos processos supra-umerais 3,50/3,67; comprimento dos processos supra-umerais $1,08 / 1,33$; comprimento dos ramos do processo mediano 0,92/1,00; distância entre os ápices do processo mediano 0,50/0,58; diâmetro maior dos glóbulos laterais do processo posterior $0,83 / 0,92$; comprimento das tégminas $5,33 / 5,25$; comprimento das asas 1,83/1,58.

Holótipo macho. Coloração geral negra, com as seguintes partes amareladas: clípeo, lóbulos supra-antenais, antenas, grande parte das verrugas do metopídio, margens laterais do pronoto incluindo os lóbulos pós-oculares e os ângulos umerais, calos látero-posteriores, anéis pré-apicais nos espinhos do processo posterior, pernas exceto as coxas e parte dos fêmures, abdome exceto os últimos segmentos.

1) Contribuição número 1204 do Departamento de Zoologia, Universidade Federal do Paraná.

2) Curso de Pós-graduação em Entomologia, Departamento de Zoologia, Universidade Federal do Paraná.

3) Departamento de Zoologia, Universidade Federal do Paraná. Caixa Postal 19020, 81531-990 Curitiba, Paraná, Brasil. Bolsista do CNPq. 


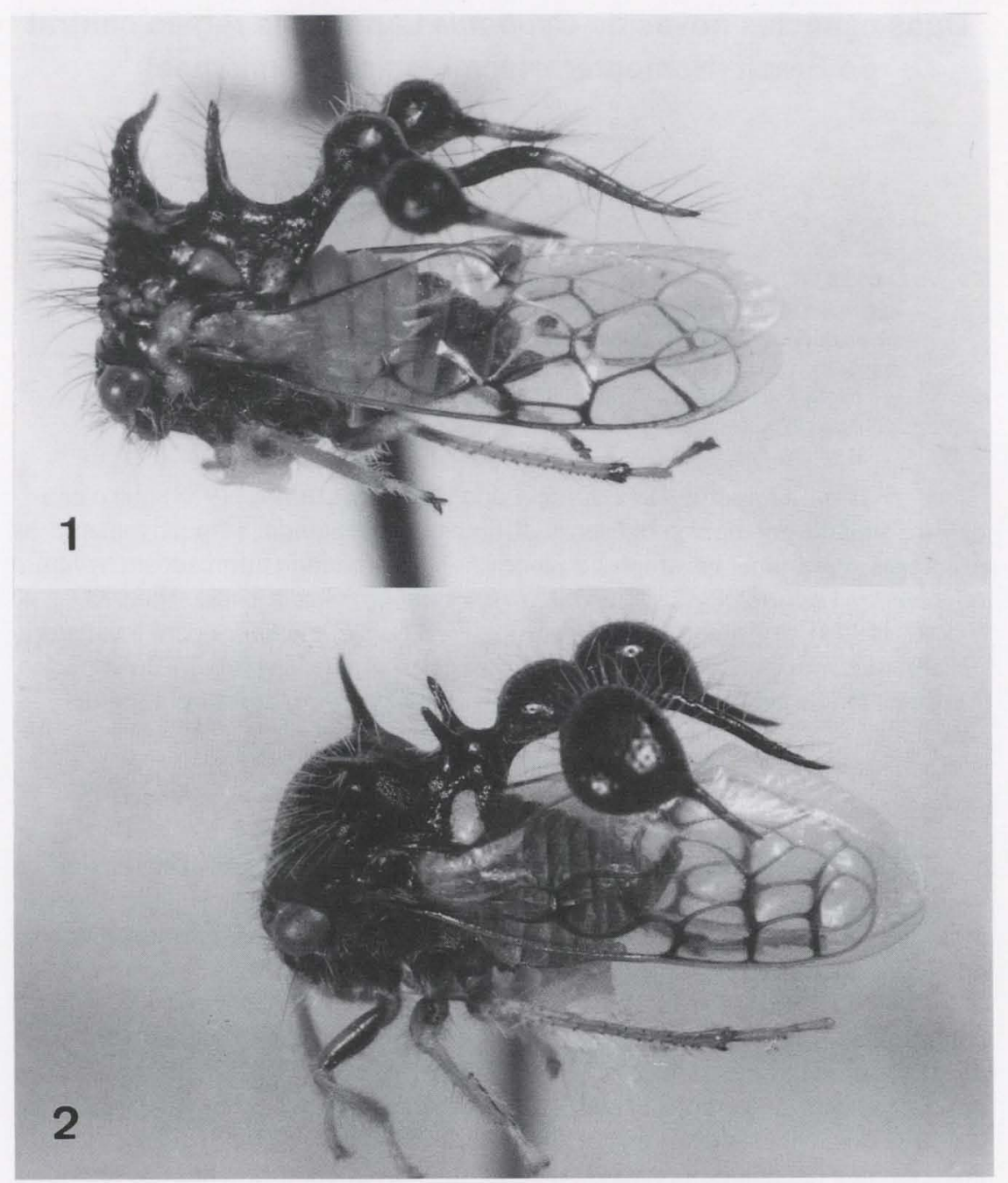

Figs 1-2. (1) Cyphonia cabetteae sp. n.; (2) Cyphonia xavantina sp. n.

Cabeça triangular, mais larga que longa; vértice bem esculturado, brilhante, com a margem superior levemente sinuosa, lóbulos supra-antenais de contorno arredondado, ligeiramente voltados para frente. Olhos globóides, salientes. Ocelos conspícuos, situados logo abaixo da linha imaginária que passa pelo centro dos olhos, equidistantes entre si e dos olhos. Clípeo ovóide, aproximadamente duas vezes mais longo que largo. Pronoto, em grande parte, liso e brilhante; metopídio distintamente verrucoso, algumas verrugas distribuídas também lateralmente acima dos ângulos umerais e na base dos processos supra-umerais. Processos supra-ume- 


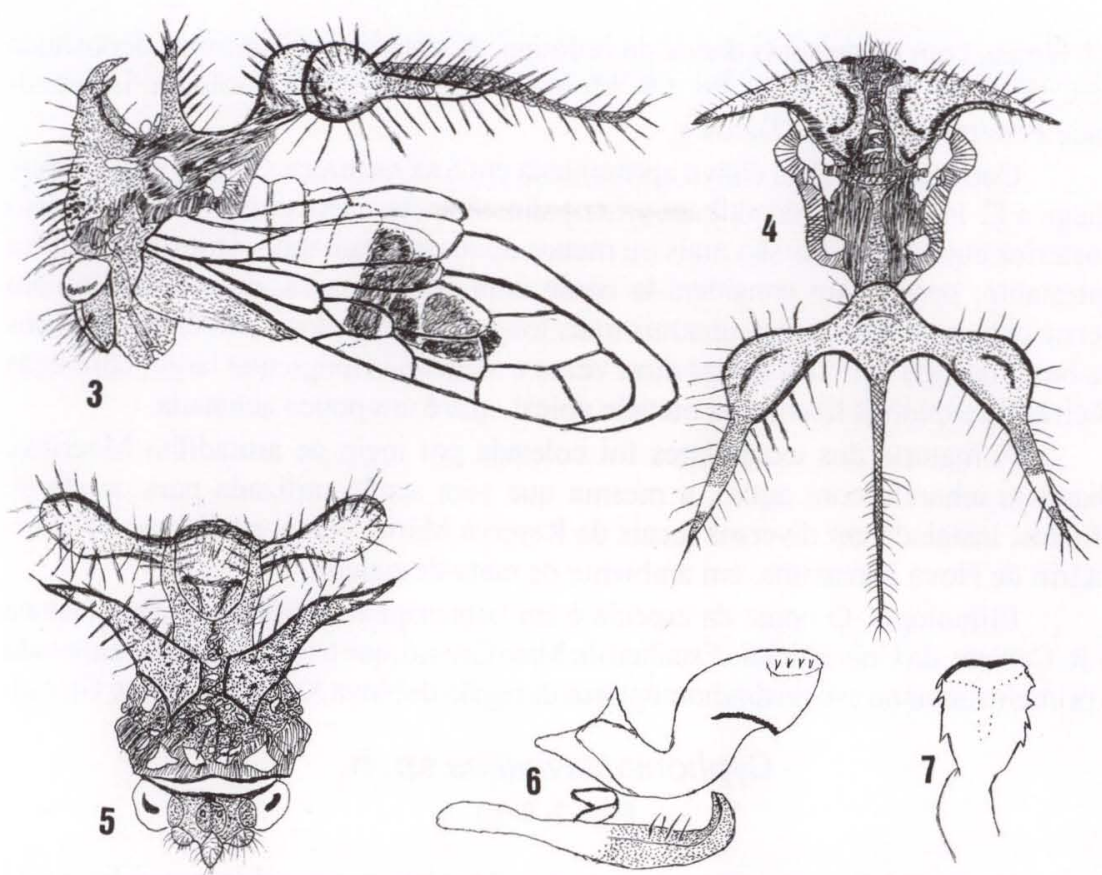

Figs 3-7. Cyphonia cabetteae sp. n. (3) vista lateral; (4) vista dorsal do pronoto; (5) vista frontal; (6) vista lateral do parâmero, conetivo e edeago; (7) ápice do edeago, vista dorsal.

rais bem desenvolvidos, mais longos que a largura da cabeça, divergentes, em vista frontal fortemente curvados para fora no terço apical, pontiagudos. Processo mediano bem desenvolvido, com os ramos delgados e ligeiramente convergentes distalmente, em vista lateral levemente inclinado para frente, elevando-se pouco acima dos processos supra-umerais e também do posterior. Margens látero-posteriores e laterais distintamente calosas, o primeiro calo logo atrás dos processos supra-umerais e o segundo no ângulo lateral. Processo posterior triglobuloso, os glóbulos laterais piriformes, aproximadamente do mesmo tamanho que o mediano; espinho mediano sinuoso, terminando pouco além da quarta célula apical das tégminas; espinhos laterais divergentes, de comprimento aproximadamente igual ao diâmetro dos glóbulos. Tégminas hialinas, com veias escurecidas principalmente no meio, e uma pequena área enfumaçada no ápice do clavo; parte basal coriácea e pouco pigmentada. Asas posteriores hialinas.

Genitália. Edeago em vista lateral duas vêzes e meia mais longo que largo, dorso plano, com pequenos espinhos na metade apical dispostos em fileiras laterais.

Fêmea. Semelhante ao macho; os processos supra-umerais são um pouco mais robustos e amarelados no ápice.

Material examinado. Holótipo macho, com os seguintes dados na etiqueta: "BRASIL, Mato Grosso, Nova Xavantina, Campus Universitário, 01 X 1996, N tomb 1134, Moericke/Mata de Galeria, Barreira, R. L. leg." Parátipos: 16 machos 
e 1 fêmea, com os mesmos dados do holótipo. A série-tipo encontra-se depositada na Coleção de Entomologia Pe. J.S. Moure, Departamento de Zoologia, Universidade Federal do Paraná (DZUP).

Comentários. Pela chave apresentada em SAKAKIBARA (1968), esta espécie chega a $C$. intermedia Sakakibara principalmente pelas características do processo posterior cujos glóbulos são mais ou menos do mesmo tamanho. Outros caracteres entretanto, permitiram considerá-la como uma espécie nova, ou seja: metopídio verrucoso; processos supra-umerais mais longos e reforçados, também verrucosos na base; edeago em vista lateral duas vezes e meia mais longo que largo, com duas fileiras de espinhos laterais na metade apical, que é um pouco achatada.

A maioria dos exemplares foi coletada por meio de armadilha Moericke (bandeja amarela com água), a mesma que vem sendo utilizada para coleta de afídeos, instalada em diversos locais da Reserva Mário Viana, no Campus Unversitário de Nova Xavantina, em ambiente de mata-de-galeria.

Etimologia. O nome da espécie é em homenagem à Professora Dra. Helena S.R. Cabette, da Universidade Estadual de Mato Grosso, que tem incentivado e apoiado o primeiro autor no estudo dos homópteros da região de Nova Xavantina, Mato Grosso.

\section{Cyphonia xavantina sp. $\mathbf{n}$.}

Figs 2, 8-13

Diagnose. Pronoto negro com pontuação relativamente fina; amarelo-creme sobre os calos nos ângulos laterais; processos supra-umerais delgados, mais curtos que a largura da cabeça; processo posterior triglobuloso, com os glóbulos laterais mais de duas vezes maiores que o mediano.

Medidas (mm). Macho (holótipo)/fêmea. Comprimento total 6,08/5,25; comprimento do pronoto $5,83 / 4,92$; largura entre os ângulos umerais $2,08 / 1,83$; distância entre os ápices dos espinhos supra-umerais $2,92 / 1,67$; comprimento dos processos supra-umerais $0,75 / 0,58$; diâmetro basal dos processos supra-umerais $0,42 / 0,33$; comprimento dos ramos do processo mediano $0,75 / 0,58$; distância entre os ápices dos ramos do processo mediano 0,75/0,50; diâmetro basal dos ramos laterais do processo posterior $0,50 / 0,42$; comprimento das tégminas $5,42 / 4,75$; comprimento das asas $2,50 / 1,83$.

Holótipo macho. Coloração geral negra com as seguintes partes amarelas: uma estreita faixa bordeando os lóbulos supra-antenais, sobre os calos dos ângulos laterais formando uma mancha ovalada amarelo-creme, as pernas, exceto as coxas, e parte dos fêmures, e o abdome.

Cabeça triangular, mais larga que longa; vértice bem esculturado, liso e brilhante, margem superior levemente arqueada, lóbulos supra-antenais com margens sinuosas e levemente voltadas para frente; olhos globosos e salientes; ocelos conspícuos situados logo acima da linha imaginária que passa pelo centro dos olhos, mais próximos entre si do que dos olhos; clípeo ovóide, aproximadamente duas vezes mais longo que largo. Pronoto, em grande parte, liso e brilhante, com pontuação fina; metopídio com pontuação um pouco mais grossa porém não verrucosa; processos supra-umerais delgados, pontiagudos, fortemente divergentes 

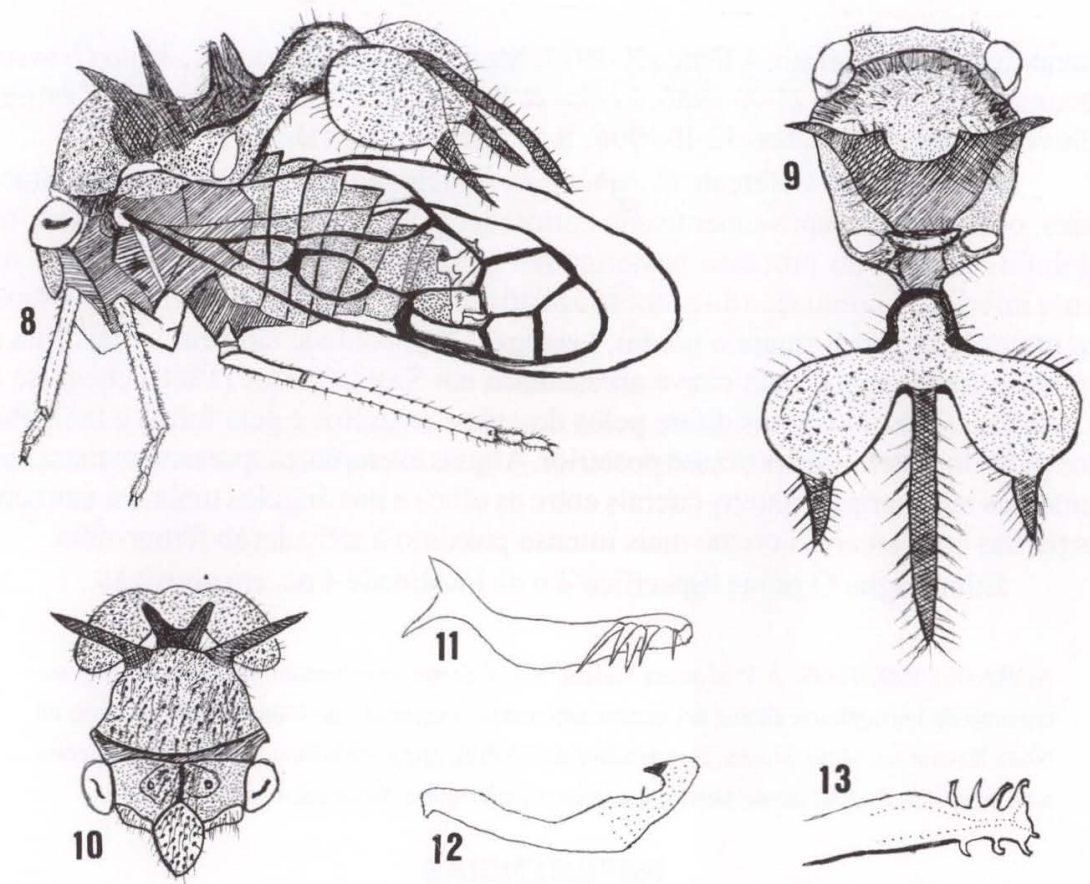

Figs 8-13. Cyphonia xavantina sp. n. (8) vista lateral; (9) vista dorsal do pronoto; (10) vista frontal; (11) edeago, vista lateral; (12) parâmero; (13) ápice do edeago, vista dorsal.

e voltados para frente, levemente curvos, de comprimento inferior à largura da cabeça; processo mediano inclinado para frente, com os ramos divegentes, mais baixo que o processo posterior; margens laterais angulosas e distintamente calosas; processo posterior triglobuloso, os glóbulos laterais fortemente inflados, com a parte dorsal bem mais convexa que a inferior, de tamanho quase três vezes maior que o glóbulo mediano; espinho mediano ligeiramente sinuoso, terminando antes do final da quarta célula apical das tégminas; espinhos laterais aproximadamente paralelos entre si, de comprimento inferior à metade do diâmetro do glóbulo. Tégminas hialinas, com veias acastanhadas, enegrecidas e coriáceas na base. Asas posteriores hialinas.

Genitália. Edeago de forma cilíndrica, visto lateralmente três vêzes mais longo que a sua largura, dorso pouco elevado, provido de duas fileiras com quatro espinhos longos situados nas laterais.

Fêmea. Semelhante ao macho.

Material examinado. Série-tipo: holótipo macho, com os seguintes dados de etiqueta: "Brasil, Mato Grosso/ Nova Xavatina, Campus Universitário, 12 III 1996, $\mathrm{N}^{\circ}$ tomb 10, Moericke/Cerrado SS, Barreira, R. L. leg.”. Parátipos: 8 machos e 2 fêmeas com os mesmos dados do holótipo ou com variações para pastagem, cerradão ou mata de galeria (DZUP). Outros espécimes: BRASIL, Minas Gerais: Barbacena 1 macho X-1973, Moure \& Mielke leg.; Pirapora, 1 fêmea XI-1977, Moure \& 
Sakakibara leg.; Corinto, 1 fềmea X-1977, Moure \& Sakakibara leg.; Mato Grosso: Diamantino, 1 fêmea 21-X-1966, Lenko \& Pereira leg.; Nova Xavantina (Campus Universitário), 44 machos 12-II-1996, R.L. Barreira leg. (DZUP).

Comentários. Difere de C. cabetteae, principalmente pelos seguintes caracteres: os processos supra-umerais são curtos, delgados, e fortemente divergentes; os glóbulos laterais do processo posterior são grandes e distintamente achatados na parte inferior. A pontuação do pronoto é relativamente fina, um pouco mais grosseira no metopídio, não formando porém, verrugas. A pilosidade também é mais fina e curta, esbranquiçada. Pela chave apresentada em SAKAKIBARA (1968) chega-se à C. clavata (Fabricius) mas difere pelos desenhos amarelos e pela forma e tamanho dos glóbulos laterais do processo posterior. Alguns exemplares apresentam manchas amarelas nas margens ântero-laterais entre os olhos e nos ângulos umerais; também as pernas com amarelo-creme mais intenso próximo à articulação fêmur-tíbia.

Etimologia. O nome específico é o da localidade-tipo, em aposição.

AGRADECIMENTOS. À Professora Helena S.R. Cabette, coordenadora do projeto "Levantamento de homópteros alados em quatro ambientes" executado no Campus Universitário de Nova Xavantina, Mato Grosso, com auxílios da CAPES, que possibilitou a captura das espécies aqui descritas. Agradecemos também, a todos aqueles que colaboraram com o projeto.

\section{REFERÊNCIAS}

SAKAKIBARA, A.M. 1968. Revisão das espécies do gênero Cyphonia Laporte (Homoptera, Membracidae, Smiliinae). Studia Entomol. 11 (1-4): 417-476.

KoPP, D.D. \& T.R. YONKE. 1979. A taxonomic review of the tribe Ceresini (Homoptera: Membracidae).

Miscell. Publ. Entomol. Soc. Amer. 11 (2): 1-97.

Recebido em 30.III.2000; aceito em 06.IV.2001. 